Supporting Information

\title{
Application of virus targeting nano-carrier drug delivery system in virus-induced central nervous system diseases treatment
}

Song Zhu, Ai-Guo Huang, Fei Luo, Jian Li, Jing Li, Long Zhu, Liang Zhao,

Bin Zhu, Fei Ling, Gao-Xue Wang*

College of Animal Science and Technology, Northwest A\&F University, Yangling 712100, China

*Corresponding author:

Gao-Xue Wang

Northwest A\&F University, Xinong Road 22nd, Yangling, Shaanxi 712100, China.

Tel./fax: +862987092102.

E-mail address: wanggaoxue@126.com (G-X. Wang). 
Table S1. Particle size and zeta potential of the constructs.

\begin{tabular}{ccc}
\hline Samples & Particle size $(\mathrm{nm})$ & Zeta potential $(\mathrm{mV})$ \\
\hline P-MWCNTs & $844.89 \pm 18.36$ & $-19.50 \pm 1.54$ \\
O-MWCNTs & $264.53 \pm 7.44$ & $-37.10 \pm 5.77$ \\
MWCNTs-PEI & $157.28 \pm 2.31$ & $+31.90 \pm 3.45$ \\
MWCNTs-PEI-R & $230.51 \pm 1.93$ & $+18.30 \pm 3.64$ \\
MWCNTs-PEI-R-Nb & $253.06 \pm 5.78$ & $-32.30 \pm 4.18$ \\
\hline
\end{tabular}




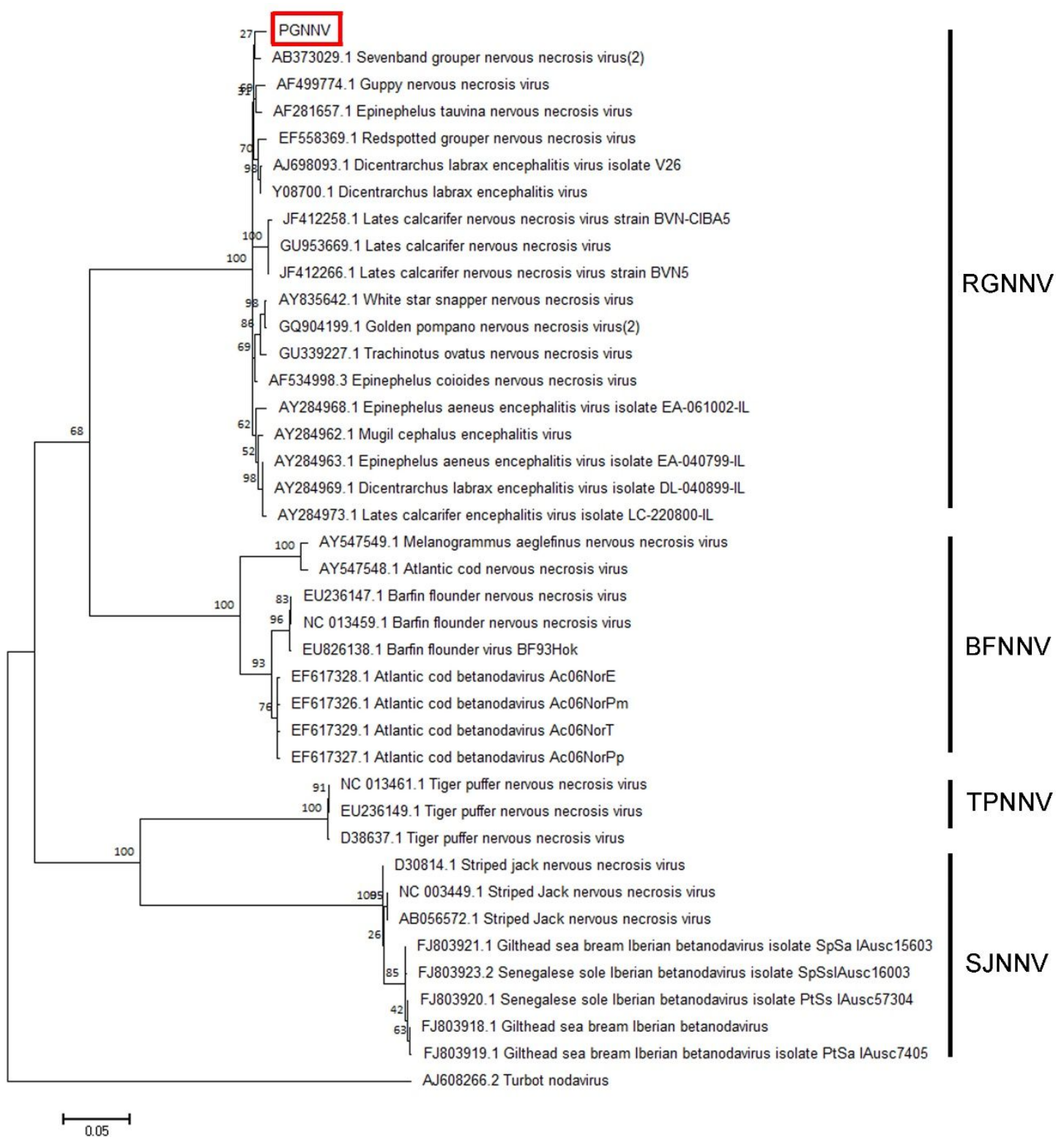

Figure S1. Phylogenetic tree deduced from analysis of the RNA2 nucleotide sequences of $38 \mathrm{NNV}$. 


$\begin{array}{cccc}\text { FR1 } & \text { CDR1 } & \text { FR2 } & \text { CDR2 } \\ \text { QVQLVESGGGLVQAGGSLRLSCAAS GHTLSGYR MAWFRQAPGKEREFVGA } & \underbrace{\text { GR3 }}_{\text {ISRNGGMTR YAD }} & \text { CDR3 } & \text { FR4 }\end{array}$

SMKGRFTISRDNGKNTVLLQMDSLKPEDTAVYYC AARTATWGTLPPDSDDYDYWGQGTQVTVSS

Figure S2. The amino acid sequence, putative complementary determining region (CDR) and framework region (FR) of nanobody used in the study. 